\title{
Sars-Cov-2 interference in HEME production: is it the time for an early predictive biomarker?
}

\author{
Giuseppe Comentale $^{1}$ (D) $\cdot$ Rachele Manzo $^{1} \cdot$ Emanuele Pilato $^{1}$
}

Received: 1 May 2020 / Revised: 5 June 2020 / Accepted: 24 June 2020 / Published online: 29 June 2020

(C) Springer-Verlag GmbH Germany, part of Springer Nature 2020

Sars-Cov-2 is a new single-stranded RNA virus that seems to have brought the entire planet to its knees in the last months. First discovered in a seafood market of Wuhan, it causes a particular kind of interstitial pneumonia and respiratory failure that results in patient's urgent need of respiratory mechanical support [1]. This has a high impact on the hospitals congestion conditioning and in turn also its mortality rate.

Sars-Cov-2 preferentially infects alveolar epithelial cells through its spike protein causing the disruption of the alveolocapillary membrane that leads to hypoxemic respiratory failure and radiological "ground-glass" pattern [2]. Infection is further characterized by high C-reactive protein and ferritin levels, anaemia and diffuse thrombosis [3, 4]. In particular, thrombosis seems to drive the entire disease course: Sars-Cov-2 infection triggers a large thrombophilic response that results in diffuse occlusion of the smaller vessels, especially in the lungs where the result is a wide thrombotic microangiopathy [5] explaining the radiologic "ground glass" pattern. This hypothesis is confirmed using clinical and autoptic evidence of diffuse arterial and vein thrombosis among Covid-19 patients [6] who benefit greatly from anticoagulant therapy [7]. This thrombophilic state could be triggered by the wide and powerful inflammatory response to the Sars-Cov-2 infection and its cytokine storm [8]. Accordingly, Covid-19 patients have high serum levels of IL-6 correlated with the severity of the respiratory failure [9]. A multicentre trial is actually ongoing to test whether Tocilizumab, a well know IL-6 blocker routinely used to treat chronic inflammation of rheumatoid arthritis, can be used to mitigate the negative effects of the inflammation and to reduce the pulmonary damage seen in these patients (ClinicalTrials.

Giuseppe Comentale

giuseppe.comentale@unina.it

1 Division of Advanced Biomedical Sciences, University of Napoli "Federico II", Naples, Italy gov Identifier: NCT04317092). Not only IL-6 but also the proinflammatory cytokine IL-1 was proposed to have a role in the overwhelming inflammatory response of infected patients [10]. Furthermore, as IL-1 was shown to be a major culprit in the development of many cardiovascular diseases [11], its involvement in the Sars-Cov-2 infection could explain the high mortality and morbidity rate among cardiopathic patients.

One of the most important lessons learned from previously treated COVID-19 patients is that early diagnosis and treatment can drastically improve the prognosis [12]. In view of this, a strategy focused on screening would guarantee the identification of asymptomatic patients where an early appropriate treatment could be the key to fighting this virus. This approach, however, needs a low cost, fast, and accurate screening method which, unfortunately, today is yet to be developed. Identifying the mechanisms by which Sars-Cov2 damages the human body, focusing on the structural proteins, could be a possible strategy to finding an effective solution. Recently, Liu et al. reported the binding capacity of some structural virus proteins, such as ORF8 and ORF10, on the porphyrins and HEME group [13]. The authors showed that the binding of these proteins could inhibit the iron inclusion in the porphyrins, causing an increase in their concentrations and a reduction in haemoglobin synthesis. In addition, ORF 10 was shown to attack the $1-\beta$ chain of the haemoglobin causing dissociation of the HEME group and the loss of its iron ions resulting in increased serum iron and in ferritin production. Free iron ions lead to an increased cellular oxidative stress and could be one of the possible mechanisms through which Sars-Cov-2 triggers the inflammatory response that destroys the lung alveolar cells. On the other hand it could stimulate ferritin production, aminolevulinic acid (ALA) synthetase transcription and, so, increased levels of porphobilinogen and ALA. Even if its involvement is not yet well described, ALA excess could explain, like in acquired acute porphyria, extrapulmonary symptoms of Covid-19 patients like gastrointestinal, neurological and neuropsychiatric 
ones. Therefore, Sars-Cov-2, like hepatitis C virus and human immunodeficiency virus, could lead to a particular form of porphyria. This mechanism could also explain why traditional molecules such as chloroquine show promising activity in treating Covid-19 patients, even if no clear evidence is available regarding the true effectiveness and safety of this drug. Severe and life-threatening side effects can usually occur, but the lack of a standardized and useful treatment makes the risk acceptable compared with the acute respiratory distress syndrome or multiorgan failure related death. It is hypothesised that chloroquine could act via an interference with the endocytosis mechanism of the virions. Furthermore, according to the identified side effects including cardiac ones (i.e., QT prolongation), probably, there are other collateral pharmacodynamic mechanisms occurring involving specific ions channels.

If demonstrated, this mechanism could be a tool to open the way to new strategies in early detection of infected individuals. From this point of view, Sars-Cov-2 seems to be very similar to malaria: many clinical and scientific reports have shown that Covid-19, not only can be successfully treated with chloroquine but also, like malaria, appears to be diagnosed much more frequently in blood group A patients [14]. Based on these results, it is reasonable to assume that low functional HEME group levels can increase their production through a positive feedback loop.

In conclusion, if an increase in HEME production pathway brings increased precursor synthesis, could we routinely dose marker for lead exposure or porphyria, such as serum porphobilinogen and aminolaevulinic acid, as biomarkers in the stages of infection? To date, there seem to be no further published or ongoing studies about the link between SarsCov-2 and porphobilinogen and ALA synthesis. These two molecules, instead of others such as ferritin or bilirubin that can increase in many conditions, could represent not only a sensitive biomarker of Sars-Cov-2 infection but also a specific and low-cost diagnostic test. Voided urine collection can be easily done at home by patients, and, unlike the nasopharyngeal swab specimen, it usually does not require healthcare intervention. Furthermore, it allows obtaining a lot of samples on which ALA and porphobilinogen can be tested. This could be useful for two reasons: it could allow reducing the impact of the infection on the health system congestion, but, on the other hand, it could also provide a useful method to screen and to follow up very quickly the population without the need of the healthcare professional intervention. In addition, if these indicators would reflect the damaging activity of the virus, they could potentially be used as a marker to monitor the response to the treatments.

Further investigations are maybe necessary to assess this role, but these hypotheses could be also a food for thought to better understand the Sars-Cov-2 pathogenetic mechanisms and to find new methods to fight against it.

\section{Compliance with ethical standards}

Conflict of interest The authors declare that they have no conflict of interest.

Ethical approval Ethical approval is not required.

\section{References}

1. Adhikari SP, Meng S, Wu YJ et al (2020) Epidemiology, causes, clinical manifestation and diagnosis, prevention and control of coronavirus disease (COVID-19) during the early outbreak period: a scoping review. Infect Dis Poverty 9(1):29

2. Kooraki S, Hosseiny M, Myers L, Gholamrezanezhad A (2020) Coronavirus (COVID-19) outbreak: what the department of radiology should know. J Am Coll Radiol 17(4):447-451

3. Henry BM, de Oliveira MHS, Benoit S, Plebani M, Lippi G (2020) Hematologic, biochemical and immune biomarker abnormalities associated with severe illness and mortality in coronavirus disease 2019 (COVID-19): a meta-analysis [published online ahead of print, 2020 Apr 10]. Clin Chem Lab Med 58:1021-1028

4. Bikdeli B et al (2020) COVID-19 and thrombotic or thromboembolic disease: implications for prevention, antithrombotic therapy, and followup [published online ahead of print, 2020 Apr 15]. J Am Coll Cardiol: S0735-1097(20)35008-7. https://doi.org/10.1016/j.jacc.2020.04.031

5. Klok FA, Kruip MJHA, van der Meer NJM et al (2020) Incidence of thrombotic complications in critically ill ICU patients with COVID-19 [published online ahead of print, 2020 Apr 10]. Thromb Res:S0049-3848(20)30120-1. https://doi.org/10.1016/j. thromres.2020.04.013

6. Porfidia A, Pola R (2020) Venous thromboembolism in COVID-19 patients [published online ahead of print, 2020 Apr 15]. J Thromb Haemost. https://doi.org/10.1111/jth.14842

7. Thachil J (2020) The versatile heparin in COVID-19 [published online ahead of print, 2020 Apr 2]. J Thromb Haemost. https:// doi.org/10.1111/jth.14821

8. Campbell CM, Kahwash R (2020) Will complement inhibition be the new target in treating COVID-19 related systemic thrombosis? [2020 Apr 9]. Circulation. https://doi.org/10.1161/ CIRCULATIONAHA.120.047419

9. Zhang $\mathrm{C}$ et al The cytokine release syndrome (CRS) of severe COVID19 and Interleukin-6 receptor (IL-6R) antagonist Tocilizumab may be the key to reduce the mortality [published online ahead of print, 2020 Mar 29]. Int J Antimicrob Agents 2020:105954

10. Parisi V, Leosco D (2020) Precision medicine in COVID-19: IL-1 $\beta$ a potential target. JACC Basic Transl Sci 5:543-544

11. Parisi V, Petraglia L, Cabaro S et al (2020) Imbalance between interleukin- $1 \beta$ and interleukin-1 receptor antagonist in epicardial adipose tissue is associated with non ST-segment elevation acute coronary syndrome. Front Physiol 11:42

12. $\mathrm{Wu} \mathrm{J}$ et al (2020) Early antiviral treatment contributes to alleviate the severity and improve the prognosis of patients with novel coronavirus disease (COVID-19) [published online ahead of print, 2020 Mar 27]. J Intern Med. https://doi.org/10.1111/joim.13063

13. Wenzhong L et al (2020) COVID-19: Attacks the 1-beta chain of hemoglobin and captures the porphyrin to inhibit human heme metabolism. ChemRxiv. Preprint. https://doi.org/10.26434/chemrxiv. 11938173.v6

14. Zhao J et al Relationship between the ABO blood group and the COVID-19 Susceptibility. medRxiv:2020.03.11.20031096. https:// doi.org/10.1101/2020.03.11.20031096

Publisher's note Springer Nature remains neutral with regard to jurisdictional claims in published maps and institutional affiliations. 